\title{
Cirandas da Vida: dialogismo e arte na gestão em saúde'
}

\section{Cirandas da Vida: dialogism and art within health}

\section{management}

\author{
Vera Lúcia de Azevedo Dantas \\ Mestre em Saúde Pública. Doutora em Educação. Coordenadora \\ pedagógica do Sistema Municipal de Saúde Escola - Secretaria \\ Municipal de Saúde de Fortaleza. \\ Endereço: Av. dos Expedicionários, 3.406, ap. 1.10I, bl. 2, Benfica, \\ CEP 60410-410, Fortaleza, CE, Brasil. \\ E-mail: dantas.verinhaळgmail.com

\section{Ângela Maria Bessa Linhares} \\ Professora doutora da Faculdade de Educação da Universidade \\ Federal do Ceará. \\ Endereço: Rua Waldery Uchôa, no I - Campus do Benfica, CEP \\ 60120-021, Fortaleza, CE, Brasil. \\ E-mail: angela.cirandaœhotmail.com

\section{Elias José da Silva} \\ Teólogo. Educador popular e coordenador das Cirandas da Vida, \\ Secretaria Municipal de Saúde de Fortaleza. \\ Endereço: Rua Humberto Lomeu, 3.231, Granja Lisboa, CEP 60541- \\ IIO, Fortaleza, CE, Brasil. \\ E-mail: elias_jsilvaळyahoo.com.br

\section{Raimundo Félix de Lima} \\ Graduado em Língua e Literaturas de Língua Portuguesa. Es- \\ pecialista em Gestão de Sistemas e Serviços de Saúde; Assessor \\ artístico-pedagógico das Cirandas da Vida, Secretaria Municipal \\ de Saúde de Fortaleza. \\ Endereço: Rua Silva Cavalcante, 777, Pirapora Maranguape, CEP \\ 61940-000, Fortaleza, CE, Brasil. \\ E-mail: limafelizœgmail.com
}

Maria Rocineide Ferreira da Silva

Enfermeira. Mestre em Saúde Pública. Doutoranda em Saúde Coletiva pela UECE-UFC. Docente da Universidade Estadual do Ceará.

Endereço: Av. Parajana, I.700, Serrinha, CEP 60000-000, Fortaleza, CE, Brasil.

E-mail: rocineideferreiraळgmail.com

\section{Luiz Odorico Monteiro de Andrade}

Professor adjunto da Faculdade de Medicina, UFC/Sobral; doutor em Saúde Coletiva pela UNICAMP, Secretário de Gestão Estratégica e Participativa do Ministério da Saúde.

E-mail: odorico_andradeळhotmail.com

I Este artigo foi baseado no trabalho apresentado à $3^{\text {a }}$ edição do Prêmio Sérgio Arouca de Gestão Participativa da Secretaria de Gestão Estratégica e Participativa do Ministério da Saúde, 2008, tendo recebido menção honrosa como "Experiências Exitosas".

\section{Resumo}

Este estudo tem como objeto as ações das Cirandas da Vida, em seu dialogismo entre o princípio da comunidade e a esfera institucional na formulação e implementação de políticas de saúde e tenta apreender como a perspectiva popular se expressa com arte na gestão em saúde. Busca capturar como as comunidades exprimem sua história de luta, mediante as linguagens da arte como fertilizadora do princípio de comunidade; analisar como os atores populares se inserem na formulação e implementação dessas políticas; compreender como os diferentes grupos geracionais expressam suas leituras da realidade, no dialogismo vivido na gestão em saúde e analisar como as linguagens da arte contribuem para a construção de atos limite como estratégias de superação das situações-limite apontadas nas rodas das Cirandas. Trabalhamos com a pesquisa ação, constituindo uma comunidade ampliada de pesquisa que procedeu à análise coletiva da experiência. A violência aponta como uma das situações limite, revelando o seu impacto na juventude em situação de conflito com a lei e as linguagens da artes surgem como potências, espaços de expressão, problematização e transgressão da realidade e do envolvimento desses jovens na construção de políticas. Revela ainda o enfoque de gênero e as estratégias de sócio-economia-solidária, bem como práticas de cuidado como atos-limite. $\mathrm{O}$ acesso aos serviços de saúde, outra situação limite apontada, revelou a necessidade de fortalecer a humanização da atenção. A arte e as práticas populares de cuidado surgem como potências dos atores populares que ocuparam rodas de gestão, incluindo seus saberes no cotidiano: o inédito viável.

Palavras-chave: Dialogicidade; Gestão; Educação popular; Arte; Saúde. 


\section{Abstract}

This study discusses the actions of the project ' $\mathrm{C} i$ randas da Vida', which works indialogism between the principles of community and the institutional field in the formulation and implementation of health policies. It tries to understand how popular perspective expresses itself artistically within health management, and to capture how communities express their history of fight through arts' languages as a fertilizer of the principle of community; we looked into how popular actors insert themselves into the formulation and implementation of these policies, in order to understand how different groups of different generations express their readings of reality, in the dialogism lived within health management. Finally, we try and analyze how arts languages contribute to the construction of limit acts as strategies to surpass limit situations which came up during Cirandas' encounters . Action research was the chosen method: an extended research community was constituted and proceeded to a collective analysis of the experience. Violence points out that it is one of the limit situations, revealing its impact onto youth with problems with the law and the potential of the languages of art as spaces of expression, problematization and transgression of reality and the involvement of these youngsters within the construction of policies. It reveals also the focus on gender, and the strategies of social and solidarity economy and care practices as limit acts. Access to health services was another limit situation pointed out, emphasizing the necessity of strengthening humanization in health attention. Art and popular practices of care emerge as potentialities of the popular actors that participated of the management encounters, bringing their knowledge in a daily basis: the viable unknown.

Keywords: Dialogism; Management; Popular education; Art; Health.

\section{A Educação Popular e o Campo da Saúde: encontros possiveis sob a ótica da gestão participativa}

A saúde coletiva insere-se em uma realidade social complexa, por isso deve ser pensada como um campo interdisciplinar, articulado a uma totalidade social. Nesse sentido, é fundamental compreendermos a importância de construir marcos que referenciem a mudança das práticas de saúde, de forma a contemplar sua historicidade mediante espaços dialógicos de interlocução entre saberes e práticas, ampliando as perspectivas de atuação e reflexão sobre a realidade na ótica da integralidade.

Podemos pensar a saúde coletiva, portanto, no contexto da produção de um processo emancipatório dos sujeitos sociais, para dar conta da complexa realidade dos serviços públicos de saúde e do diálogo que devem estabelecer com os movimentos sociais. Situamos, assim, inicialmente, a educação popular e saúde como um braço do movimento popular, na luta pelo direito à saúde.

A articulação entre saúde e doença, nesse contexto, faz-se com base na concepção de saúde como processo de conquistas sociais amplas, que incorpora aspectos das subjetividades, no caminho de exercer-se como direito, percebendo tratar-se da produção da vida coletiva que se tece, porém, no traçado singular das culturas.

As políticas de saúde, no Brasil, têm passado por mudanças significativas nos últimos vinte anos, que refletem as conquistas populares no sentido da democratização dos serviços e do acesso da população aos processos decisórios. O Sistema Único de Saúde (SUS) é emblemático dessas mudanças, no entanto, é preciso percebê-lo como um projeto social em construção.

Segundo Oliveira (1994), vivenciamos no Brasil um movimento em que a sociedade busca redefinir e redesenhar o Estado a partir de uma ampla conjugação de variadas forças, em que as classes populares tentam a criação de uma sociedade política que se erga com novos parâmetros de justiça social.

Pensar o SUS sob a ótica da integralidade e da humanização significa situar os cidadãos como centro da organização das práticas de saúde, a serem pautadas nos desejos e necessidades da população. 
Em que pese os extensos e graves desafios que permanecem, é possível vislumbrar cenários, nos quais as ações de saúde estejam voltadas para o enfrentamento dos seus condicionantes, possibilitando encontros entre profissionais, gestores e população.

Espera-se que esses encontros sistemáticos (práxis formativa) fortaleçam a formação política dos sujeitos populares, atores sociais capazes de "vir-a-ser-mais" (Freire, 1999) e de produzirem novos saberes que contribuam para a inclusão social e a promoção da vida.

Ao refletirmos sobre a gestão em saúde, não podemos nos distanciar das lutas que historicamente foram travadas pela conquista do SUS no qual o controle social, representado pelos conselhos de saúde, institui-se enquanto política. Apesar desse espaço instituído, é na tensão permanente entre a sociedade organizada e as esferas de governo que novos direitos constituem-se e fazem-se valer aqueles já instituídos.

0 presente estudo emerge da caminhada de homens, mulheres, jovens e crianças que compõem as rodas das Cirandas da Vida, atividade de educação popular situada no contexto do Sistema Municipal de Saúde Escola e insere-se no contexto de uma gestão pública municipal, buscando fazer o movimento dialético de desvelar o mundo, partindo da ação-reflexão-ação (Freire, 1999).

Nesse sentido, a pergunta geradora destas reflexões foi: como poderíamos ler o dialogismo e a arte na gestão em saúde, buscando a perspectiva popular? Para dialogar sobre essas questões, elegemos o relato da experiência viva em ato a partir do diálogo entre a Comunidade Ampliada de Pesquisa, Comunidade Ampliada de Pares, os círculos de cultura e a arte.

Campos (2006) chama a atenção para a necessidade de estruturação de arranjos organizacionais que facilitem e mesmo estimulem a construção de vínculos, a "longitudinalidade", a responsabilização clínica e sanitária entre gestores, trabalhadores e usuários. Esses mecanismos teriam como principal objetivo potencializar a democratização das organizações de saúde, apontando para a possibilidade de cogestão da saúde coletiva e da clínica.

Para o autor, cogestão implica um modo de administrar em que o pensar e o fazer coletivo constituem-se diretrizes ético-políticas, objetivando democratizar as relações no campo da saúde. Portanto pensar processos que apontem para a cogestão dos diversos espaços institucionais no campo da saúde coletiva pressupõe reconhecer os cenários de disputa, micropoderes e as diferentes concepções de saúde que constituíram as práticas nesses espaços.

Também pressupõe o reconhecimento dos diversos atores como sujeitos - protagonistas dessas práticas e a necessidade de potencializar a autonomia desses diversos sujeitos, possibilitando a construção de diálogos e escutas sob a ótica da saúde como direito dos cidadãos e cidadãs.

O fortalecimento de espaços de gestão participativa no SUS implica no envolvimento da população na construção das políticas de saúde e no compromisso com a autonomia das pessoas, ampliando os espaços públicos para o exercício do diálogo e das pactuações, respeitando as diferenças.

Essas reflexões nos levam a alguns questionamentos necessários a esse processo de elaborações:

Como pensar caminhos no campo da saúde coletiva, em que gestores, profissionais e população possam interagir e descobrir, juntos, formas coletivas de aprendizagem e investigação?

Como construir a problematização da realidade complexa do nosso cotidiano de trabalho numa perspectiva transformadora da realidade?

Como efetivamente promover a inclusão popular nos espaços de gestão e na construção do processo de trabalho em saúde? Que diálogos seriam possíveis e constituiriam as condições de possibilidade para que as transformações necessárias ocorram?

Merhy (2002) fala sobre o trabalho em saúde como trabalho vivo em ato cujo objeto não é plenamente estruturado, possibilitando certo grau de liberdade na forma de realizá-lo, incluindo subjetividades a partir de tecnologias leves (aquelas voltadas para o campo relacional e destituídas de poder pela mecanização e tecnificação dos atos em 
saúde) implicadas com a produção de relações entre os vários sujeitos envolvidos: os profissionais, os gestores e a população.

Nesse contexto, a educação popular oferece um instrumental teórico-fundamental para o desenvolvimento dessas novas relações, "através da ênfase ao diálogo, a valorização do saber popular e a busca de inserção na dinâmica local” (Vasconcelos, 2001, p.14), tendo a identidade cultural como base da ação educativa, e compreendendo que o "respeito ao saber popular implica necessariamente o respeito ao contexto cultural" (Freire, 1999, p. 86).

A Secretaria Municipal de Saúde de Fortaleza adotou a Estratégia Saúde da Família como estruturante da rede de serviços de saúde do SUS no município, buscando a ampliação efetiva da cobertura assistencial. Nesse percurso tem se orientado por critérios de avaliação de risco e vulnerabilidade nos diversos territórios da cidade, como estratégia de estabelecer prioridades na ampliação do acesso aos serviços. Ao mesmo tempo tem buscado construir um desenho organizativo e uma proposta de gestão que potencialize a efetiva participação dos diversos atores institucionais, na tentativa de constituir espaços coletivos para análise das informações e tomada das decisões.

Nesse sentido, a gestão constitui, como arranjos, as Rodas da Gestão que perpassam pelos territórios "vivos", as Redes Assistenciais e as políticas estruturantes do Sistema na perspectiva de descentralizar e democratizar os processos da gestão e de tomada de decisão (Fortaleza, 2006). Andrade e colegas (2006, p. 121) desenharam, para o Sistema, a Teia da Cogestão da Produção de Saúde, que, de forma transversal, alimenta a interface da gestão e da atenção das redes assistenciais, constituindo teias "que dão suporte à cogestão do cuidado, dando vida e materializando o SUS que queremos - universal, com integralidade, equidade e participação social.” As Cirandas da Vida foram nomeadas na Teia da Cogestão como Roda da Educação Popular em Saúde e incluídas no colegiado gestor da Secretaria Municipal de Saúde (figura 1).

Figura I - Teia da Cogestão de Produção da Saúde no Sistema Municipal de Saúde de Fortaleza

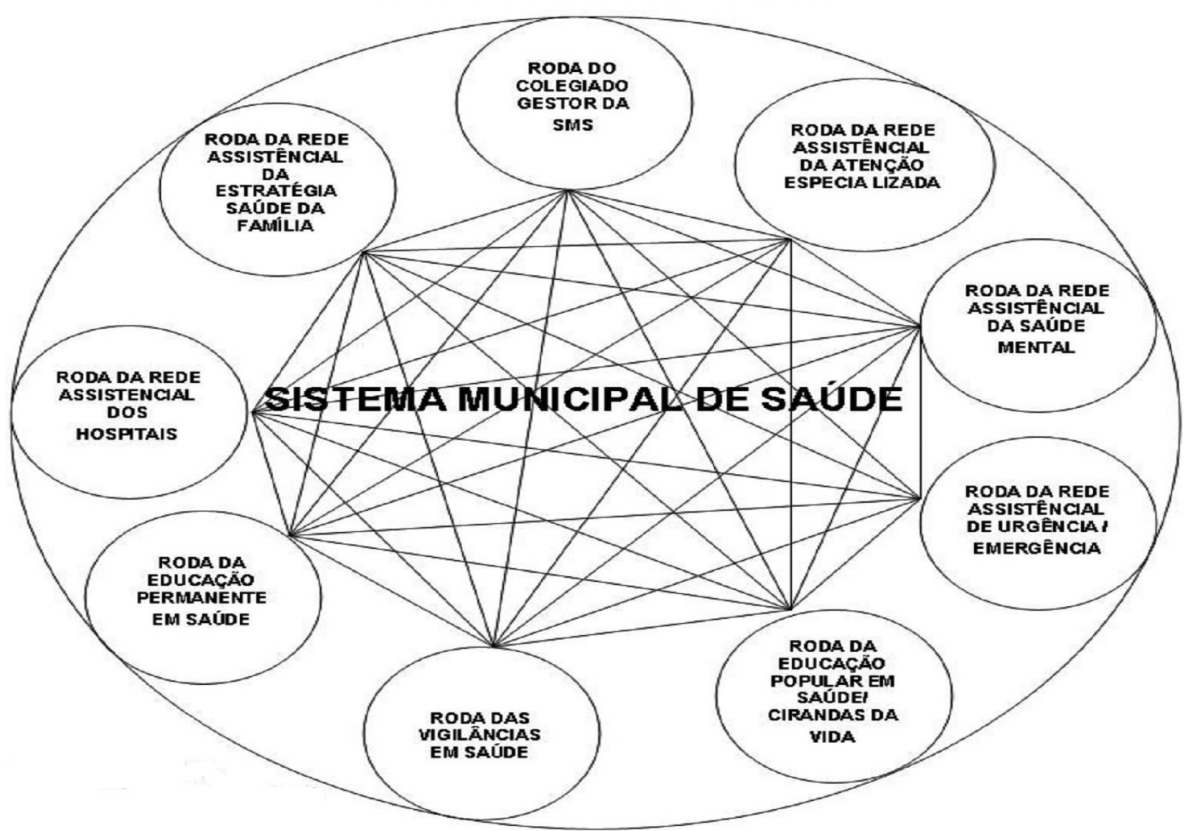

Fonte: Canuto, O. M. C.; Andrade, L. O. M. Fortaleza, 2006 
Nessa perspectiva caberia interrogar: que pontos de ruptura e que dificuldades esses novos desenhos de participação e organização dos serviços evidenciam? Em que medida as rodas de gestão constituídas nas diversas redes assistenciais da saúde em Fortaleza promovem a inclusão dos atores populares, considerando a proposição de Campos (2006) de fazer comportar, nesses espaços, além dos gestores e trabalhadores do campo da saúde, a sociedade civil, os cidadãos e seus familiares?

Segundo relatório de gestão da Secretaria Municipal de Saúde, o enfrentamento dos desafios presentes no campo da gestão e da atenção, "requerem a implementação de uma política de educação para o SUS" que potencialize a mudança do modelo médico-assistencial e qualifique o processo de gestão participativa e democrática (Fortaleza, 20o6).

Ao nos referirmos à gestão participativa, nós nos remetemos à concepção apontada por Pedrosa (2008) "como compartilhamento do poder nos processos que constroem e decidem as formas de enfrentamento aos determinantes e condicionantes da saúde, bem como a presença do conjunto dos atores que atuam neste campo". Ainda segundo o autor, gestão participativa refere-se ao aprofundamento de processos e mecanismos que possibilitem o alargamento da participação social nas políticas públicas e a constituição de espaços em que, a partir da explicitação das diferenças, podem-se construir proposições coletivas e arranjos institucionais que venham operacionalizar respostas às necessidades sociais reveladas.

Nesse contexto, a Secretaria Municipal de Saúde de Fortaleza adota, como política estruturante de organização e de gestão do serviço, o Sistema Municipal de Saúde-Escola - SMSE.

\section{Um Sistema para Efetivar as Transformações Necessárias: articulando forças}

A ideia-força que orienta o Sistema Municipal de Saúde-Escola é potencializar a reorientação do modelo assistencial, propiciando mudanças qualitativas no processo de trabalho em saúde, contextualizadas em uma vivência educacional que tem como protagonistas: gestores, trabalhadores da saúde, ins- tituições formadoras e as diferentes representações dos movimentos sociais e populares. O SMSE nasce com o intuito de fortalecer e consolidar a estratégia da Educação Permanente no município de Fortaleza, em dezembro de 2006, através da Portaria 160/2006, publicada no DOM de 04/o1/o7. É importante frisar que ele se articula aos movimentos que hoje pautam as discussões sobre a Educação Permanente em Saúde e às instituições formadoras no Estado.

As Cirandas da Vida surgem por iniciativa de atores e atrizes vinculados à Articulação Nacional de Movimentos e Práticas de Educação Popular e Saúde-ANEPS e inserem-se no contexto do Sistema Municipal Saúde-Escola - SMSE (BARRETO, et al, 2006) - objetivando a inclusão da educação popular nas ações educativas deste sistema, a partir da dialogicidade, da problematização, da criatividade e essencialmente do "saber-de-experiência-feito" (Freire, 1999) dos diversos sujeitos implicados, na perspectiva de construção da autonomia.

\section{As Trilhas Desenhadas na Comunidade Ampliada de Pesquisa}

As singularidades das trilhas (violência, humanização e moradia na área de risco) construídas na caminhada das Cirandas da Vida, ao buscar a perspectiva popular na luta pelo direito à saúde, questionando como o princípio de comunidade e a esfera institucional dialogam na formulação e implementação de políticas no campo da saúde em uma gestão popular, nesse contexto maior de dialogismo, em que a arte se explicita como caminho nessa busca da perspectiva popular em saúde e a esfera da instituição, é que pautamos o relato desta experiência.

Nesse itinerário, outras questões dão contorno à pergunta inicial: como a população das comunidades envolvidas nas rodas das Cirandas da Vida, projeto da gestão atual, expressam - em seu dialogismo - as diversas dimensões da sua história de luta mediante as linguagens da arte?

Ao chamar a arte ao contexto dialógico desse projeto, perguntávamos por dimensões da vida que constituem a saúde das comunidades envolvidas nas suas rodas, expressas nas falas populares.

Existem, no Ceará e em outros Estados do Brasil, diversas experiências envolvendo arte e saúde. 
No entanto, a maioria delas têm se remetido a uma dimensão instrumental da arte, que reduz a compreensão dos contextos nos quais o dizer da arte articula sentidos e diálogo.

No âmbito deste estudo, a arte é compreendida como espaço de criação - transcendência, capaz de produzir sentidos, trajetos, sentimentos, contribuindo para construir as trilhas do caminho, dos projetos de futuro e dos atos que ultrapassam limites e transformam realidades. Refutamos a ideia de arte como instrumento, e a entendemos como dimensão que potencializa a dialogicidade criativa, capaz de realizar a suspensão crítica em que se promove a reflexão das ações - situações vividas e se favorece a escuta em rede da experiência coletiva.

Dessa forma, os propósitos da experiência das Cirandas da Vida em Fortaleza - CE são: compreender como se expressam o dialogismo e a arte, na gestão em saúde, buscando a perspectiva popular; capturar como a população das comunidades envolvidas nas rodas das Cirandas da Vida expressa as diversas dimensões da sua história de luta, mediante as linguagens da arte como fertilizadora do princípio de comunidade; identificar como a luta pelo direito à saúde se expressa nas rodas populares, no contexto das Cirandas da Vida, em seus enfrentamentos com a esfera institucional; analisar como os atores e atrizes populares se inserem na formulação e implementação de políticas no campo da saúde, a partir das rodas das Cirandas da Vida; entender como os diferentes grupos geracionais percebem e expressam suas diversidades de leituras da realidade, no dialogismo vivido no contexto da gestão atual em saúde.

\section{Trilhas e Teias para um Trabalho em Rede: contextualizando a proposta}

Lançadas em meados de 2005, as Cirandas da Vida colocam em cena o desafio de desenhar coletivamente uma proposta de educação popular que construa um olhar multirreferencial na interface entre atores populares e institucionais, para dialogar sobre ações de enfrentamento às situações-limite apontadas pela população, especialmente nas áreas de maior vulnerabilidade social de Fortaleza.
Tendo como ponto de partida a reconstituição coletiva da memória social desses territórios, expressas como suas histórias de luta e resistência, os atores sociais envolvidos nas rodas das Cirandas da Vida têm apontado situações-limite e potencialidades, construindo possibilidades de transformação da vida do lugar, a partir de atos-limite.

Nessa perspectiva caberia interrogar: em que medida as rodas de gestão constituídas nas diversas redes assistenciais da saúde em Fortaleza promovem a inclusão dos atores populares e como as rodas populares das Cirandas dialogam com esses espaços instituídos da gestão?

Nesse sentido as Cirandas da Vida, ao trazerem a perspectiva popular para o campo da gestão, vão delineando, a partir do campo da saúde, trilhas nas quais é possível articular esses dois campos: o da perspectiva popular e o da esfera institucional.

Um dos aspectos significativos da proposta é a inclusão de atores e atrizes dos movimentos populares como protagonistas da construção dessas rodas populares que denominamos Cirandas. Ao se incluírem na esfera institucional, trazem a tensão permanente entre ação política e o fortalecimento dos espaços organizativos do movimento e da comunidade e vão realizando a mediação entre esses dois espaços, renovando as relações sociais cotidianas, incluindo novos sentidos para a ação governamental, revitalizando-a, chamando-a a pensar coletivamente e a ouvir a comunidade em seus desejos e necessidades. Esse caminhar revela-se um campo tenso de recuos e limites, de onde se impulsiona o pluralismo necessário para fazer comportar as vozes populares.

Outra dimensão da experiência das Cirandas da Vida diz respeito aos espaços de escuta e diálogo propiciados aos gestores, em sua interface com os atores de várias gerações. A possibilidade de participar dos diálogos intergeracionais evidencia a diversidade de olhares no cotidiano das comunidades que refletem a complexidade a ser enfrentada pelos espaços institucionais na construção das políticas.

Outro aspecto relevante da experiência é a possibilidade de trabalhar pensando a integralidade do território, com suas culturas, suas potencialidades e seus desafios de estruturar atos-limite que devem tentar romper com a fragmentação setorial. Para caminhar em direções tão difíceis de serem vividas 
na prática, temos de nos perguntar constantemente: como incorporar o saber construído na vivência cotidiana como estratégia de resistência dos setores oprimidos e como estratégia de redesenhar e operacionalizar as políticas?

As Cirandas têm afirmado, em sua constituição, a necessidade de promover um processo permanente de interação entre os diversos setores no campo da saúde e de todas as políticas sociais nas seis loco-regiões administrativas de Fortaleza. Segundo Andrade (2006, p.282), um processo intersetorial aponta para a constituição de um espaço em que novas práticas e saberes vão se construir "com base nos problemas concretos e complexos que a realidade apresenta". Para o autor, os diversos setores contribuem com essa construção, a partir de seu acúmulo histórico, organizacional, teórico e metodológico, gerando um novo objeto com suas práticas, saberes e identidade que, por sua vez, são mediados por esses acúmulos.

Nessa perspectiva a caminhada das Cirandas aposta na possibilidade de construção coletiva e intersetorial de atos-limite capazes de reconhecer a possibilidade de promover a vida e construir o inédito viável, categoria fundamental ao desenvolvimento do processo, definido por Freire como:

"Uma palavra que traz nela mesma o germe das transformações possíveis voltadas para um futuro mais humano e ético. Uma palavra que carrega no seu âmago, crenças, valores, sonhos, desejos, aspirações, medos, ansiedades, vontades e possibilidade de saber, fragilidade e grandeza humanas" (1999).

\section{Situações-Limite: o lugar de se problematizar as transformações}

As situações-limite são aqui entendidas como aquelas que exigem transformação no contexto local, por dificultarem a concretização dos sonhos, desejos e necessidades coletivas das populações. Para Freire (1987), as "situações-limite" envolvem trabalharmos os "percebidos destacados" e, ainda, se referem à chegada de dimensões humanas e tarefas históricas e concretas das pessoas, em sua atuação social:

[...] não devem ser tomadas como barreiras insuperáveis, além das quais nada existisse. No momento mesmo em que os homens as apreendem como freios, é que elas se configuram como obstáculos à sua libertação, se transformam em "percebidos destacados" em sua "visão de fundo". Revelam-se assim, como realmente são: dimensões concretas e históricas de uma dada realidade. Dimensões desafiadoras dos homens [...] (p. 9o).

Os encontros e oficinas das Cirandas da Vida vêm possibilitando a construção de espaços de escuta à população, capazes de potencializar os processos de territorialização, planejamento e avaliação permanentes vividos por algumas equipes da Estratégia Saúde da Família em Fortaleza; proporcionando o fato de que o saber gestado nesses espaços possa alimentar as práticas de saúde locais.

A tentativa de incorporar abordagens populares como Farmácias Vivas, Terapia Comunitária, Massoterapia, Reiki, entre outras, no contexto dos serviços públicos de saúde, além de potencializar as práticas culturais da comunidade como estratégias de promoção e cuidado à saúde, têm criado caminhos que vão nessa direção de escuta popular.

Pinçamos aqui um aspecto importante: o caráter dialogal dessa "busca" de escuta às experiências As comunidades apontam as situações-limite vivenciadas e, então, estudam-se as potencialidades locais para o seu enfrentamento, tentando buscar a memória coletiva dos grupos e pessoas. Os limites são vistos de diversos ângulos - os "percebidos destacados".

A partir da definição das situações-limite, são estruturadas oficinas temáticas, articuladas com instituições e movimentos que trabalham e atuam com o tema-problema, com o objetivo de estudar e realizar enfrentamentos coletivos no âmbito das regiões envolvidas, sempre partindo das potencialidades locais de luta.

A problematização parte de um mergulho na memória, fazendo a reconstituição da história do grupo e dos problemas, norteada por perguntas geradoras, expressas e socializadas através de rodas de conversa, círculos de cultura e das linguagens da arte. 0 reencontro das pessoas das diversas comunidades com essa memória tem explicitado desafios importantes a serem enfrentados pelo conjunto dos atores.

Outro aspecto importante considerado nessa proposta diz respeito ao envolvimento de crianças, 
adolescentes e jovens nos grupos geracionais que protagonizam diferentes ações, na tentativa de participar dos momentos de reconstituição da história do seu bairro. Cabe aqui ressaltar a importância desses atores sociais na percepção dos problemas do lugar; no entendimento do que sejam as potencialidades e nas formas como contam dos seus desejos e sonhos sobre o espaço urbano.

O aprofundamento temático é feito com base na articulação entre os vários saberes e na tentativa de contribuir com o processo de reorganizar a atenção - o que se presume permitir ampliar o olhar sobre a questão.

O processo de construção dessas reflexões tem envolvido expressões artísticas como teatro, cenopoesia, música, hip-hop, artes plásticas, entre outras, produzidas coletivamente a partir de perguntas geradoras que buscam traçar os diferentes percursos e perfis das situações- -limite apontadas e que representam, também, a possibilidade da emergência do lúdico, do simbólico, dimensões em geral subtraídas dos processos formativos e de pactuação política.

Nesse sentido, a arte, por sua capacidade de permanecer vinculada às fontes da vida e da morte das comunidades (Linhares, 2003), envolve a criação de laços solidários e comprometidos com a libertação, constituindo-se como elo que articula saberes diferenciados, sensibiliza os diferentes atores envolvidos e exprime as representações que o homem constrói a partir da sua leitura do mundo na perspectiva de conhecer e intervir sobre a realidade. (Geertz,1989).

Outra dimensão fundamental da experiência diz respeito à possibilidade de os diversos atores envolvidos na construção da proposta, especialmente os atores populares a que chamamos cirandeiros, exercitarem a construção da autoralidade. 0 diálogo pressupõe uma ideia de conhecimento que inclui o saber como algo que é produzido por todo o corpo social e que cada pessoa recompõe quando aprende. Dessa forma constituímos uma comunidade ampliada de pesquisa na qual esses atores populares percebem-se autores de suas falas individuais e coletivas e discutem como organizar a experiência dos grupos com quem lutam, trazendo o campo expressivo do outro. Este, não só se diz oralmente, mas desenhando, pintando, cantando, cenopoetizando, dramatizando, enfim, traz sua riqueza expressiva de um modo mais abrangente.

Os principais desafios apontados nesse percurso dizem respeito ao envolvimento dos atores institucionais (gestores e trabalhadores) com a possibilidade de re-conhecimento e inclusão dos "saberes-deexperiência-feitos" e a captação de recursos para o desenrolar das ações que por vezes esbarram nas barreiras da burocracia institucional. A construção da intersetorialidade e da multirreferencialidade que considere os saberes do mundo da vida tão importantes quanto os técnicos, tem se configurado como outra questão relevante a ser enfrentada.

\section{Movimentos para uma Ciranda da Cidade}

Nos registros produzidos sobre as situações-limite trabalhadas nas seis regionais de Fortaleza, estão apontadas: a violência, a dificuldade de acesso aos serviços de saúde e a moradia na área de risco A análise dos indicadores construídos na Comunidade Ampliada de Pesquisa desvelaram potencialidades locais para a superação das situações-limite apontadas.

Em quatro, dos seis territórios trabalhados pelas Cirandas, a violência foi apontada como uma situação-limite priorizada pelo conjunto dos atores, revelando singularidades tais como: o impacto dessa violência para a juventude de algumas regiões, revelando a necessidade de construção de atos-limite para um coletivo de jovens que estão em situação de vulnerabilidade social mais profunda; como jovens em situação de conflito com a lei, e adolescentes e jovens em situação de exploração sexual.

As linguagens da arte têm-se revelado espaços de criação, formação, problematização e transfiguração da realidade, potencializando o envolvimento desses jovens na construção de políticas tais como orçamento participativo, políticas de juventude, esporte e lazer e a aproximação com a comunidade escolar, favorecendo o envolvimento com processos formativos, a produção de círculos de cultura e a estruturação de redes de arte, cultura e saúde.

Nesse processo a arte, para o conjunto dos atores infanto-juvenis, tem se revelado também como principal ato-limite para o enfrentamento da questão. Eles reconhecem nessas expressões a possibilidade 
de ocupar espaços que se vêm constituindo cenários de produção de violência, reconfigurando-os na perspectiva de promover a vida.

No que diz respeito à dificuldade de acesso aos serviços de saúde, esses desafios afirmaram a necessidade de redimensionamento da atenção à saúde prestada, expressa no desejo de um maior diálogo e respeito à comunidade. Emergiram, assim, trilhas temáticas no contexto das dificuldades de acesso aos serviços de saúde: humanização das ações; organização da atenção à saúde e participação popular.

A humanização tem sido um dos principais focos da discussão, permeando as três trilhas acima descritas e suscitando a necessária convergência de caminhos que tenham por base o diálogo, a solidariedade e a compreensão de que o fazer compartilhado torna a humanização possível.

No que se refere aos espaços instituídos de gestão participativa que, no contexto de Fortaleza, foram nomeados rodas de gestão, as Cirandas, através de seus atores protagonistas, os cirandeiros, ocuparam com arte esses espaços, problematizando a questão da participação dos usuários nas rodas, produzindo uma tensão permanente entre o princípio de comunidade e a esfera institucional. Dessa forma, em alguns centros de saúde da família, deuse a inclusão dos atores populares. Por outro lado, os cirandeiros, atores comunitários ocupando um espaço na gestão em saúde, ao participarem das rodas regionais ou mesmo do coletivo gestor da secretaria municipal de saúde, promoveram essa inclusão comunitária na gestão.

Adiscussão acerca das dificuldades de moradia nas áreas de risco possibilitou a reflexão sobre as diversas dimensões do tema-problema, revelando a necessidade de problematizar as causas e determinantes da ocupação do mangue em uma determinada região da cidade e seus impactos sobre a vida dessas pessoas.

No processo outras questões foram evidenciadas tais como: a ausência de políticas de geração de emprego e renda, o confronto entre as leis de proteção ambiental e a realidade concreta de pessoas vivendo em ambientes hostis, onde a falta de oportunidades gera agressões ao ambiente e impacto sobre a saúde dessas pessoas.

Outro aspecto importante refere-se à participação das crianças, que protagonizam diferentes ações ao participarem dos momentos de reconstituição da história do seu bairro, colocando-se como moradores que percebem os problemas do lugar; apresentando o que entendem como potencialidades e falando dos seus desejos e sonhos sobre espaço urbano.

Com assento garantido nas rodas das Cirandas, as crianças são sensibilizadas a expressarem sua compreensão do lugar onde vivem, por meio de desenhos, música, teatro, dança e outras manifestações artísticas, mostrando o quanto estão conectadas com as questões que permeiam o seu cotidiano. Protagonizando processos, interferem no direcionamento e na tomada de decisões, influenciando as demais gerações.

Freire (1999) refere-se à multiculturalidade não como justaposição de culturas ou como poder exacerbado de uma sobre as outras, mas propõe uma liberdade conquistada, em que cada cultura se move e respeita a outra, dialogando criticamente e construindo novos cenários de prática social. Haveria uma cultura da infância?

Dos relatórios primeiros, das Cirandas da Vida, escuta-se:

Esses corpos diminutos cheios de graça crescem e se equilibram nas pernas de pau e falam, cantam, gesticulam a contar uma história de caminhantes que peregrinam por uma cidade tão grande, mas onde não conseguem um lugar para morar... Escutemos como se dizem:

Dona Mariquinha se eu pedir você me dá

Um lugarzinho pra gente poder morar

$\varepsilon$ elas cantam pra contar pedaços da história. Assim as dificuldades de moradia...

Pipoca amendoim torrado

A chuva era grossa e derrubou o meu barraco

A participação das crianças foi reveladora da necessidade de incluí-las nos processos de discussão e transformação da realidade, resguardando aquilo que é próprio do seu momento de vida: o aprender a partir do universo infantil e a partir do seu saber de experiência feito, como propõe Paulo Freire.

Diante de uma realidade marcada pela dificuldade de acesso à escola, falta de oportunidades de profissionalização e de lazer, os jovens elaboraram suas estratégias de enfrentamento e as expressões 
culturais surgiram como alternativas concretas de resistência e transcendência da realidade.

A fala do cirandeiro, Thyago, advindo do Movimento Nacional de Meninos e Meninas de Rua, traz para o centro da discussão a problemática da juventude envolvida com o crime, a exploração sexual, como ele diz com a linguagem do rap:

Olha a Fortaleza Bela

Nesse imenso arquipélago

De bairros e favelas

Sua área de maiores contradições

$\varepsilon$ a regional II

Onde pequenas porções de riquezas

São cercadas por bolsões de pobreza

Nesse território, a questão da violência, para os jovens, surge de forma bastante contundente. Os grupos de juventude apontam a violência gerada pela falta do acesso aos direitos básicos de cidadania, que se expressam no tráfico de drogas e vão desaguar na discriminação e no cerco de negações conhecido como "mundo dos jovens em conflito com a lei".

As narrativas juvenis, como a do hip-hop, mostraram sua potência como crônica social. Despertam o interesse e o respeito dos participantes, e em musicalidade, ritmo e letra expõem um conteúdo social verdadeiro; com uma imagética rica, abordam a comunidade de modo criativo e situam o político em todos os espaços da vida da juventude da periferia.

A participação dos jovens envolvidos diretamente com a violência trouxe um olhar diferenciado sobre a questão:

Graças à participação desses sujeitos vida loka é que tivemos como situação-limite a violência que atinge a juventude e não a violência da ótica da segurança pública como queriam os líderes comunitários.

Os jovens destacam as múltiplas dimensões da violência sob a ótica da exclusão social: o não-acesso às políticas públicas de saúde, educação, trabalho, moradia. Falam da ausência de oportunidades de profissionalização, do "falseado" acesso à escola, da inexistência de áreas de lazer e da violência policial que geram uma reação em cadeia e ocasionam a organização dos jovens em níveis correspondentes de violência.
Os enfrentamentos propostos quase sempre buscam as formas culturais de se expressar, compreender e se relacionar com o mundo do bairro e a sociedade. As experiências com arte aparecem como grandes oportunidades.

Como um dos frutos desse diálogo, deu-se a implantação de uma turma do projeto Adolescente Cidadão do Governo Federal, executado em parceria com a Fundação da Criança da Cidade do Município de Fortaleza (FUNCI), dirigida para jovens em situação de conflito com a lei:

Em relato e estudo grupal, pudemos pensar:

[...] os enfrentamentos tentam fazer reviver a esfera sistêmica, alargando o dialogismo vivido nos grupos intergeracionais, agora junto à esfera institucional. Contudo, como manter vivo o princípio de comunidade, em meio à hierarquização dos serviços públicos? Como deixar claro que não se trata de "fazer pelo estado", mas fazer com que a esfera sistêmica possa dispor do poder analítico dos movimentos sociais, da riqueza de sua experiência, de sua construção de saberes múltiplos e do conhecimento da cultura na qual se inserem?

[...] na SER II estamos trabalhando o foco dessa juventude vida loka na perspectiva que eles participem da construção das políticas. O projeto "craques só de bola" foi organizado numa parceria das Cirandas com a Central Única das Favelas-CUFA e está trazendo para dentro da escola os jovens que foram expulsos dela - porque a grande maioria dos jovens que estão fora da escola foram expulsos por ela.

Da narrativa do cirandeiro, é possível apreender uma dificuldade de reconhecimento, nas instituições públicas, da atuação da juventude. A visão de participação popular e do princípio da comunidade como massa de mobilização (instrumentalizadora e redutora) ainda é preponderante, como se pode ver:

[...] Uma outra ação que estamos tentando realizar é a oficina de Acolhimento ao Adolescente que foi construída com as entidades que trabalham com esses jovens Esta, ainda não iniciou porque as unidades de saúde não encontraram tempo para enviar um profissional. "Sónos reconhecem quando se trata de mobilizar a comunidade para eleição do conselho local de saúde." 
Na perspectiva de construir atos-limite para o enfrentamento da violência, foi elaborada uma proposta de atuação junto a 15 escolas públicas municipais, onde artistas e educadores populares adentraram o espaço pedagógico da escola para trabalhar, a partir das linguagens da arte, o tema da violência com os estudantes.

Ancorado nessas linguagens, as Cirandas da Vida refletem e valorizam as potencialidades de atores e grupos juvenis que, abrangendo as diversas regiões de Fortaleza, constituem-se como espaço de produção de saberes e sentidos, a partir dos quais consideramos a possibilidade de promover a ampliação da percepção de seres humanos enquanto sujeitos criativos e afetivos, bem como propiciar a participação popular e o protagonismo infantojuvenil na promoção da saúde e da qualidade de vida. As linguagens da arte arrogam-se como espaço de aprendizagens e reflexões críticas para revelar as várias dimensões da questão estudada desse modo coletivo.

As ações nas escolas principiaram sob o protagonismo de artistas-educadores e cirandeiros apoiados no acompanhamento dos gestores das escolas, dos distritos de saúde e educação, além dos diversos atores envolvidos nos processos formativos do Sistema Municipal de Saúde Escola de Fortaleza. A proposta tem como ponto de partida a reconstituição da história de luta e resistência das escolas sob o olhar de seus vários atores e a problematização das situaçõeslimite vivenciadas através das linguagens da arte.

A caminhada evidencia a necessidade de rediscutir a proposta com o conjunto dos atores na perspectiva de maior apoio da escola e inserção na proposta pedagógica, assim como fortalecer a interface com a unidade de saúde e com outros setores que potencializem a inclusão de outras ações e políticas sociais para o contexto da comunidade.

A escuta aos adultos é reveladora de um trabalho em rede que ajuda a socialização das estratégias de luta e resistência. A tematização da violência revelou o enfoque de gênero e as trilhas apontaram atoslimite como incubadoras femininas, feiras e outras estratégias de sócio-economia-solidária, grupos de arte e processos formativos com esse enfoque.

A dificuldade de acesso aos serviços de saúde revelou a necessidade de fortalecer a humanização da atenção. As práticas populares de cuidado e as linguagens da arte como o teatro, a música, a produção de Histórias em Quadrinhos, surgem como atos-limite possíveis sob o protagonismo dos atores populares que ocuparam as rodas de gestão das unidades e apontaram para a inclusão de outros olhares e práticas no cotidiano do trabalho em saúde, como a Terapia Comunitária, Massoterapia, Grupos de auto-estima, entre outros.

Nesse contexto a interação com a ANEPS potencializou o fortalecimento de um espaço no campus da Universidade Estadual do Ceará - Espaço Ekobé - como forma de estabelecer diálogos entre os saberes disciplinares da universidade, aqueles desenvolvidos na prática profissional e os gestados a partir das experiências de movimentos populares. Desse modo, foram sendo pensadas ações em campos como cultura, cuidado em saúde, formação, a partir das necessidades percebidas pelos diferentes atores do processo, procurando integrá-las aos currículos universitários, processos de educação permanente desenvolvidos nos serviços de saúde e práxis dos movimentos populares. Criou-se, assim, um espaço de encontro em que esses diversos atores passaram a enxergar as possibilidades de uma práxis compartilhada que pudesse fortalecer a todos e destacar o saber popular, tantas vezes negligenciado, como também significativo.

As práticas integrativas e complementares de cuidado existentes no contexto dos movimentos populares de Fortaleza têm representado a principal singularidade da atuação do Espaço Ekobé que mantém há um ano um calendário de práticas como Massoterapia, Reiki, Reflexologia, rezas, entre outras, disponibilizadas a estudantes, trabalhadores e pessoas das comunidades. Por outro lado, esses atores dos movimentos têm ocupado esse espaço, referenciando-se como facilitadores de processos formativos, inclusive nos cursos de graduação e pósgraduação, ocupando também agendas políticas no que diz respeito às ações de educação permanente em saúde, realizando uma espécie de extensão comunitária.

Por fim, a temática da moradia em área de risco trouxe a necessidade de problematizar as causas e determinantes da ocupação do mangue e seus impactos sobre a vida dessas pessoas. No processo 
outras questões foram evidenciadas, tais como: a ausência de políticas de geração de emprego e renda, o confronto entre as leis de proteção ambiental e a realidade concreta de pessoas vivendo em ambientes hostis, onde a falta de oportunidades gera agressões ao ambiente, e os impactos sobre a saúde das pessoas. Por outro lado, a participação de atores institucionais de vários setores da gestão municipal trouxe, para as pessoas que residem no território, a possibilidade de escuta às suas necessidades e a conquista de algumas questões como a coleta de lixo, a liberação de casas para a área de maior vulnerabilidade, ação no território da equipe de saúde da família.

\section{No Caminhar, Algumas Lições Aprendidas}

O reencontro da ciência com o saber popular, saber de experiência feito segundo Paulo Freire, remetenos à necessidade de um saber plural, em saúde coletiva, em que os profissionais de saúde, gestores e a comunidade possam vislumbrar atos-limite. Dessa forma, subverte-se a dominação e estabelece-se o novo - o inédito que é possível, como nos ensina o autor.

Boaventura Sousa Santos (1998) alerta-nos para a ideia de que todo paradigma em ciência deve ser um paradigma social, que deve exigir vida digna para todos. A complexidade da realidade que nos é apresentada exige a perspectiva multicultural, entendida como criação histórica - desejo e utopia de sujeitos diferentes, trazendo o singular de suas culturas para uma ação comum.

Dessa forma, a caminhada com as Cirandas da Vida vêm nos fazendo pensar nos possíveis espaçoscenários de dialogicidade entre saberes diferenciados. Bordando falas, narrativas, gestos, será que as diversas linguagens da arte podem ajudar a construir novos sentidos, atos-limite no tempo de agora para os processos educativos e de gestão?

Nesse sentido a experiência com as Cirandas da Vida nos orienta a fazer uma suspensão crítica sobre a realidade social que estamos a vivenciar, buscando tecer conexões entre os microuniversos das comunidades e sujeitos-atores/atrizes envolvidos(as) com a complexidade do tecido social.
Esperamos que as Cirandas da Vida possam contribuir para delinear possíveis percursos pedagógicos e de gestão como referências para os trabalhadores da saúde em que seja possível partilhar experiências e a própria crítica, lançando-se mão da expressão oral, da narração e da memória social de forma a estimular a criação de laços solidários comprometidos com a emancipação humana, vista também como a chegada das potencialidades dos sujeitos, em suas amplas dimensões.

\section{Referências}

ANDRADE, L. O. M. A saúde e o dilema da intersetorialidade. São Paulo: Hucitec, 20o6. v. 1, p. 293.

ANDRADE, L. O. M.; BUENO, I. C. C.; BEZERRA, R. C. Atenção primária à saúde e estratégia de saúde da família. In: CAMPOS, G. W. S. et al. A educação permanente e a construção de sistemas municipais de saúde-escola: o caso de Fortaleza (CE). Divulgação em Saúde para Debate, Rio de Janeiro: v. 34, p. 31-46, 2006.

CAMPOS, Gastão W. S. Saúde Paideia. São Paulo: Hucitec, 2006.

FREIRE, P. Pedagogia do oprimido. 35. ed. Rio de Janeiro: Paz e Terra, 1987.

FREIRE, P. Pedagogia da esperança: um reencontro com a pedagogia do oprimido. 6. ed. Rio de Janeiro: Paz e Terra, 1999.

FORTALEZA. Relatório de gestão 2005: saúde, qualidade de vida e a ética do cuidado. Fortaleza, 2006. 274 p.

GEERTZ, C. A interpretação das culturas. Rio de Janeiro: LTC, 1989.

LINHARES, A. M. B. O tortuoso e doce caminho da sensibilidade: um estudo sobre a arte e educação. 2. ed. Iju:Unijui, 2003.

MERHY, E.E. Saúde: a cartografia do trabalho vivo. São Paulo: Hucitec, 2002.

OLIVEIRA, F. Estado, sociedade, movimentos sociais e políticas públicas no limiar do século XXI. Conferência debate promovida pela FASE/ PIC. Rio de Janeiro: FASE/PIC, 1994. 
PEDROSA, J. I. S. Educação popular em saúde e gestão participativa no Sistema Único de Saúde.

Revista APS, Juiz de Fora v. 11, n. 3, p. 303-313, jul./

set. 2008

SANTOS, B S. Um discurso sobre as ciências. 10.

ed. Porto: Edições Afrontamento, 1998.

VASCONCELOS, E. M. (Org.). A saúde nas palavras

e nos gestos: reflexões da rede de educação

popular e saúde. São Paulo: Hucitec, 2001.

Recebido em: 27/04/2011

Aprovado em: 03/10/2011

58 Saúde Soc. São Paulo, v.21, supl.ı, p. 46-58, 2012 